\title{
Modeling of Complex Apron Conflict Control Based on Petri Net Model
}

\author{
Weijun Pan, Lei Yang*, Xinping Zhu, Qinghai Zuo, Rundong Wang, Chuyang Yang, Jie Luo and Youjun Ye \\ Affiliation: School of Air Traffic Control, Civil Aviation Flight University of China, Guanghan in Sichuan, 618300, China \\ ${ }^{*}$ Corresponding author
}

\begin{abstract}
This paper uses discrete events modeling to apron surface activity control problem. Through dispersing runway taxiway and apron, discrete element map to Petri net basic element, build surface activity model based on Petri net. The paper build model of apron activity by Petri net theory, use Cpntools simulate real apron activity, analysis and assess real activity efficiency of aircraft, prove validity of model and improve apron efficiency.
\end{abstract}

\section{Keyword-petri net model; cpntools}

\section{INTRODUCTION}

Petri net theory research organization structure and dynamic activity of system, eyes on every kind of possible changes and relation between the changes. Petri net can describe system structure well, show parallel synchronization conflict and so on, simulate discrete events system briefly and directly by net diagram, it is suited to describe system organization structure and system condition changing .Petri net is developed, have a kinds of net system ,such as condition/event net, placeltransition net. These nets benefit for modeling of complex system. Petri net applys to design computer science.

This paper firstly discrete surface activity such as apron and apron axiway based on safety, models and simulates surface activities in an extended period, calculate and compares the activities, proves that controler model according to Petri net theory and applicability of rule.

\section{MODELING}

\section{A. Linear Inequality Based on Petri Net}

As for discrete event system, we need control the activities so that conform to special rules, the major rules divided into 5 types: (1) resource conflict; (2) deadlock; (3) order norm; (4) buffer overflow; (5) operation rule; All of states about controling in system space can map to allow and forbid. And in Petri net model, many controling problems can transform into net system that conform to limit of a linear inequality. So we can make requirement of system into controlling problems of limit of a linear inequality.

linear inequality:

$$
l \cdot m \leq b
$$

In the equation, 1 means $\mathrm{n}$ dimensional place weighting vector quantity, every one of weighting vector is integer, parameter $b$ means threshold value of sum of weighting vector.

Controling goal make system meet the demands of a linear inequality, every one linear inequality can be:

$$
\sum_{i=1}^{n} l_{i} m\left(p_{i}\right) \leq b
$$

\section{B. Apron Using Rule \\ 1)Rule of controling 1}

Based on safety of apron, only allow one aircraft push-back or push-in.

$$
m(\text { cross })+m(\text { park }) \leq 1
$$

\section{2)Rule of controling 2}

Aircraft run from taxiway to apron, or from apron to taxiway, must enter the PB position, if position is not empty, wait here.

$$
m(p b)=1, \text { full; } m(p b)=0, \text { empty } .
$$

\section{AIRPORT GATE MODEL}

Discretize apron sector as the FIGURE 1,set a apron with a push-back, build the relate model. Build model for aircraft in or out. The pl1_out and pl1_in means number 1 push-back and push-in, controler c_1 make only one aircrft in or out,pl1_limit means gate position indicate controler. Then build the model by cpntools as FIGURE 2 .

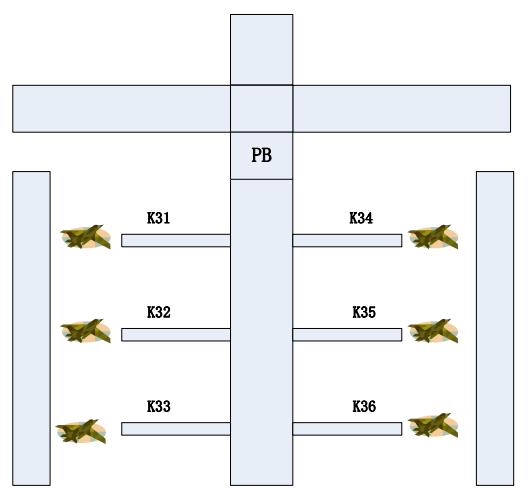

FIGURE I. DISCRETIZE APRON SECTOR 


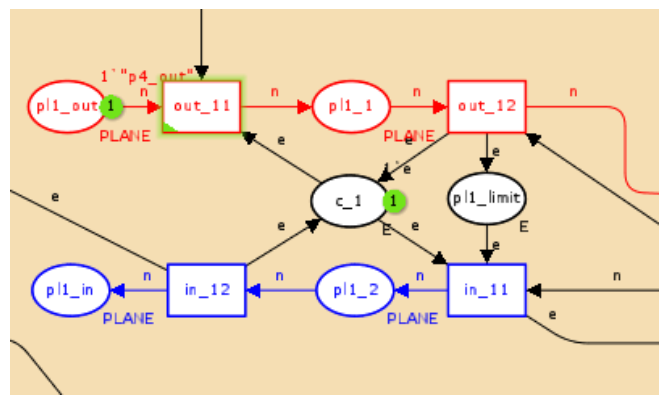

FIGURE II. GATE POSITION MODEL

With the same way, build activities model of push waiting and taxiway in and out. Place CROSS and CROSS_1 means direction of taxiway to apron, place $\mathrm{pb}$ and $\mathrm{pb} \mathrm{C}_{-}$means direction of push waiting position to apron,c1 means make only one aircraft run, so, get the following FIGURE 3.

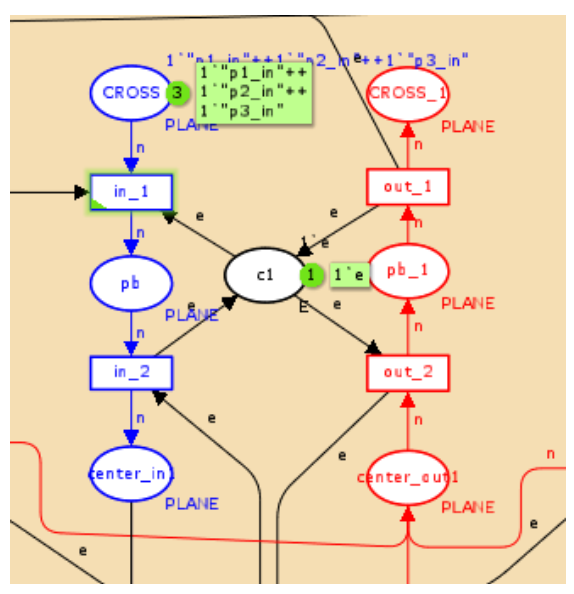

FIGURE III. TAXIWAY MODEL

Apron taxiway possibly have conflict of center, so need controler c 12 and c 34 make exclusiveness of center resource, build the model as FIGURE 4.

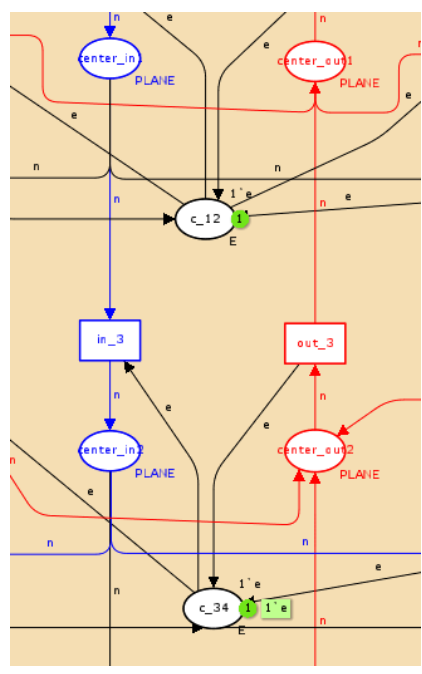

FIGURE IV. CENTER MODEL
These are major function model. Through these controler model and apron activities model, simulates real apron aircraft activities, assess the efficiency of aircraft in these models.

\section{EXPERIMENT CALCULATION}

Function fun Trantime line is used for calculating crossing time of straight taxing, speed is set as $\mathrm{SS}=10 \mathrm{~m} / \mathrm{s}$; function fun Trantime cur is used for crossing time of turn a corner, turn speed is $\mathrm{SC}=5 \mathrm{~m} / \mathrm{s}$; function fun Transtren $\mathrm{L}$ is used for crossing time of center. We test a part of Flight time plan TABLE1.

TABLE I. FLIGHT TIME PLAN

\begin{tabular}{|c|c|c|c|}
\hline number & Departure/arrival & ETOA/ETOP & gate \\
& & & \\
\hline P1 & A & $13: 10: 00$ & K31 \\
\hline P2 & D & $13: 11: 55$ & K32 \\
\hline P3 & A & $13: 11: 40$ & K33 \\
\hline P4 & D & $13: 12: 50$ & K34 \\
\hline P5 & D & $13: 14: 50$ & K35 \\
\hline P6 & D & $13: 17: 00$ & K36 \\
\hline
\end{tabular}

Set average time, from runway to taxiway need 40s. Set two push-back position. Simulate the data as the following FIGURE 5.

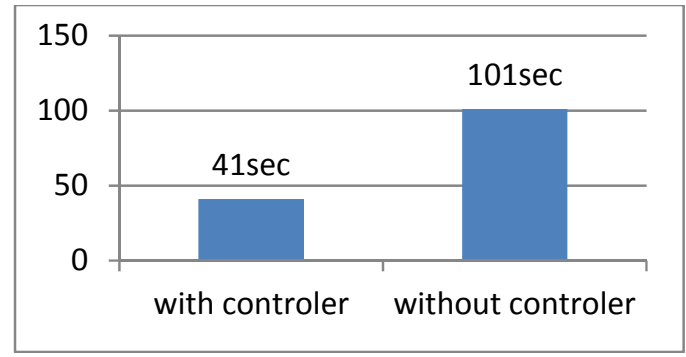

FIGURE V. SIMULATE REAULT

The result prove that use of controler can improve efficiency of apron activities, control the apron conflict so that less delay.

\section{ACKNOWLEDGMENT}

Project supported by the National Natural Science Foundation of China (Grant No. U1433126)

Project supported by innovation project (Grant No. X2015-27).

\section{REFERENCES}

[1] Jun Tang,Miquel Angel Piera,Toni Guasch. Coloured Petri net-based traffic collision avoidance system encounter model for the analysis of potential induced collisions[J]. Transportation Research Part C,2016,:.

[2] M. Taleb,E. Leclercq,D. Lefebvre. Control Design of Timed Petri Nets via Model Predictive Control with Continuous Petri Nets[J]. IFAC Proceedings Volumes,2014,472:

[3] Frank Schumacher,Sebastian Schröck. Transforming hierarchical concepts of GRAFCET into a suitable Petri net formalism[J]. IFAC Proceedings Volumes,2013,469:

[4] Michal Kutil,Zdeněk Hanzálek. Light Controlled Intersection Model Based on the Continuous Petri Net[J]. IFAC Proceedings Volumes,2009,4215:. 
[5] Agnes Madalinski,Victor Khomenko. Predictability Verification with Parallel LTL-X Model Checking Based on Petri Net Unfoldings *[J]. IFAC Proceedings Volumes,2012,4520:

[6] Tatiana R. Shmeleva,Dmitry A. Zaitsev. A Parametric Colored Petri Net Model of a Switched Network[J]. Int'l J. of Communications, Network and System Sciences,2011,0401:

[7] Zhang Ling. A Petri net based formal model of Hypermedia[J]. Wuhan University Journal of Natural Sciences, 1999,42 : 